Acta Theriologica 35 (1-2): 17-24, 1990.

PL ISSN $0001-705$ I

\title{
The food of otters Lutra lutra in different habitats in Hungary
}

\author{
Ildikó KEMENES and Gábor NECHAY
}

\begin{abstract}
Kemenes I. and Nechay G. 1990. The food of otters Lutra lutra in different habitats in Hungary. Acta theriol. 35: 17-24.

The diet of otters was studied by the method of spraint analysis. Remains of over 800 prey items were found in 270 spraints. Among these the proportion of fish was over $80 \%$. We found no preference for any particular species of fish but small or medium-sized specimens were the most frequent in the diet. The composition of the otter's diet may reflect that of the fish stock in a particular pond or lake rather than selective predation. Nearly half of the consumed fish were considered as economically unimportant and about $20 \%$ of them were classed as economical pests.

Hungarian Natural History Museum, Budapest, Baross u. 13, 1088 - Hungary (IK); Ministry for Nature Protection and Water Management, Budapest, Költö u. 21, 1221-Hungary (GN)

Key words: diet, prey selection, Lutra lutra, Hungary
\end{abstract}

\section{Introduction}

Otters Lutra lutra (Linnaeus, 1758) were common throughout Europe in the early part of this century, but have declined markedly in many countries during the last few decades (see Mason and Macdonald 1986, for review). In Hungary otters have been protected since 1978 and according to our recent survey (I. Kemenes, in prep.) there are still abundant populations all over the country. Because of the very specific ecological requirements of this species, their presence is however much more conspicuous in the vicinity of pond cultures and fish farms. In such places fishermen urge the killing of otters and keep applying to the conservation authorities for shooting permits. The main reason for these applications is based on anecdotal opinions claiming that otters are blood-thirsty predators killing much more fish than they are able to consume and besides, always selecting the bigger and economically more valuable specimens from the stock. There is now a number of detailed studies available on the feeding habits of otters in various countries which contradict these statements (Erlinge 1968, 1969, Waisfeld 1973, Chanin 1981). Moreover, in Hungary no study on the feeding of otters has been undertaken so far. Therefore we have examined the food composition of otters living in different habitats in order to elucidate the food habits of this endangered species and to verify or falsify the above-mentioned claims. Such an analysis is necessary to reach a solution acceptable to both fish-farmers and conservationists.

\section{Material and methods}

The prey of otters was studied by spraint analysis. This method has already successfully been used for the analysis of the food composition of otters (Erlinge 1967, 1968, 1969, Rowe-Rowe 1977, Jenkins 1980, Tumanov 1980, Chanin 1981). 
Fresh scats were collected in the winter and spring period weekly or biweekly in five study areas. After washing the spraints through filters $(0.05 \mathrm{~mm}$ pore diameter $)$ and drying them, the remains of prey items were separated. Fish species were identified by comparing vertebrae, otoliths, teeth and scales found in the samples with reference collections and studies on fishes (Frost 1928, Dyk 1956, Berinkey 1966, Webb 1976, Wise 1980, Marz 1987). Other vertebrates were determined from the skeletal remains, teeth, hair and feathers. Invertebrates were identified from their integuments.

The frequency of occurrence of fish in the spraints was estimated from the number of otoliths, eye lenses and teeth found in the scats. Where only scales were present, only a minimum estimate was possible. Here, the minimum number of individual prey items was considered to be equal to the number of different species these scales belonged to. The sizes of consumed fishes were estimated from the size of their anterio-caudal vertebrae found in the scats. The only reference available on the correlation between the length of vertebrae and the body length of fishes are measurements on pike and eel by Jenkins et al. (1970) and Wise (1980).

\section{Study areas \\ The Ócsa landscape protection area}

The 3500 ha peat bog is a relict of the post-pleistocene marsh lands between the rivers Danube and Tisza. It has been protected since 1975 . Otters range on 100 ha of the entire area where the open water surface is about $150-600$ ha depending on the season and weather (i.e. the highest water level is normally found in early spring). Amphibians, fish and birds are abundant. The most common fish species are Umbra krameri, Lepomis gibbosus, Ictalurus nebulosus and other cyprinids.

\section{Somogyfajsz}

The 28 ha area is cultivated by an anglers' association. There is an oak forest around the fishpond and the 10 ha water surface is surrounded by reed (Phragmites communis). Cyprinus carpio and Hypophthalmichthys molitrix are regularly released by the association. Besides these, the fish stock mainly consists of Tinca tinca, Scardinius erythrophthalmus, Carassius carassius, Abramis brama and Esox lucius.

\section{Veresegyház}

The 10 ha pond is almost completely surrounded by the village and weekend cottages and a section of the shore is used as a beach. There is dense reed cover in and around the pond, which belongs to an anglers' association. Cyprinus carpio and Hypophthalmichthys molitrix are released by the association and these are the most common species in the stock.

\section{Lake Balaton}

Lake Balaton is the largest lake in Hungary; its water surface covers $588 \mathrm{~km}^{2}$ and it contains $1.8 \times 10^{7} \mathrm{~m}^{3}$ water. Average depth of the lake is $2-3 \mathrm{~m}$ but the southern part is more shallow and in the northern part is deeper than average. The shore is densely inhabited and the entire lake district is a very busy resort in summer. The dominant component of the aquatic vegetation is reed (Phragmites communis). The most common members of the fish fauna are Alburnus alburnus, Aspius aspius, Abramis brama, Cyprinus carpio, Anguilla anguilla, Scardinius erythrophthalmus, Pelecus cultratus, Blicca bjoerkna, Rutilus rutilus and Tinca tinca. Hypophthalmichthys molitrix were released in 1972. The population of Lepomis gibbosus is constantly declining.

\section{Kis-Balaton Nature Reserve}

This 1800 ha area has in effect been protected since 1922, in spite of being gazetted as a protected area only in 1951. Formerly it was an integral part of the much larger Lake Balaton but now it is a marsh land 
formed by the deposits of the river Zala. A new dyke system was built in 1985. The open water surface covers 180 ha and average water depth is $1.2 \mathrm{~m}$. The dominant vegetation is reed (Phragmites communis). Trees are scarce in this area and consist of Almus, Populus and Salix species. The main components of the fish fauna are the same as in Lake Balaton but the species Esox lucius and Carassius carassius are predominant.

\section{Results \\ Food composition}

The remains of 811 prey items were found in 270 spraints. Although fish predominated in the diet of the otters in all five areas, insects, molluscs, amphibians, reptiles, birds and mammals also contributed to the diet. The percentage frequency of occurrence of different prey categories is shown in Table 1.

Table 1. The frequency of occurrence of different prey categories in spraints from five study areas.

\begin{tabular}{lccccc}
\hline Item & $\begin{array}{c}\text { Balaton } \\
(\%)\end{array}$ & $\begin{array}{c}\text { Kis-Balaton } \\
(\%)\end{array}$ & $\begin{array}{c}\text { Ócsa } \\
(\%)\end{array}$ & $\begin{array}{c}\text { Veresegyház } \\
(\%)\end{array}$ & $\begin{array}{c}\text { Somogyfajsz } \\
(\%)\end{array}$ \\
\hline Fish & 86.14 & 83.56 & 81.09 & 90.65 & 67.32 \\
Mammals & 3.63 & 5.48 & 2.10 &. & 2.61 \\
Birds &. & 4.11 & 2.10 &. & 1.97 \\
Amphibians & 3.30 &. & 0.84 &. &. \\
Reptiles & 0.99 &. &. &. &. \\
Insects & 3.96 & 6.85 & 13.87 & 3.74 & 28.10 \\
Molluscs & 1.98 &. &. & 5.61 &. \\
\hline Total number & & & & & 153 \\
of items & 303 & 73 & 238 & 107 & 153 \\
\hline
\end{tabular}

A more detailed analysis was carried out on the predominant fish prey categories. Spraints from the five different areas were analyzed to compare the composition of fish consumed (Fig. 1). Although nearly the same fish categories (families) are present in the different habitats like Ócsa, Lake Balaton and Kis-Balaton, their proportions in the spraint samples varied considerably. Based on correlations established by Jenkins $e t$ al. (1979) and Wise (1980) the calculated percentage occurrence of different size categories of pike and eel in the samples are shown in Figs 2 and 3. Of pike the remains of small $(10-15 \mathrm{~cm})$ specimens were the most common. The largest pike in the samples $(2$ specimens) were about $30-40 \mathrm{~cm}$ long. Of eels, specimens of $32-42 \mathrm{~cm}$ body length appeared to be selected by the otter. This size is considered small for eels. The biggest eel in the samples ( 1 specimen) was $50 \mathrm{~cm}$ long.

Predation in relation to the economic importance of fish prey species

All fish species identified in the spraint samples were categorized as being economically important, indifferent or noxious. The fish species were allocated to one of the three categories following Berinkey (1966). Remains of fishes belonging to the families Cyprinidae, Cobitidae, Esocidae, Anguillidae and Ictaluridae were found in the 

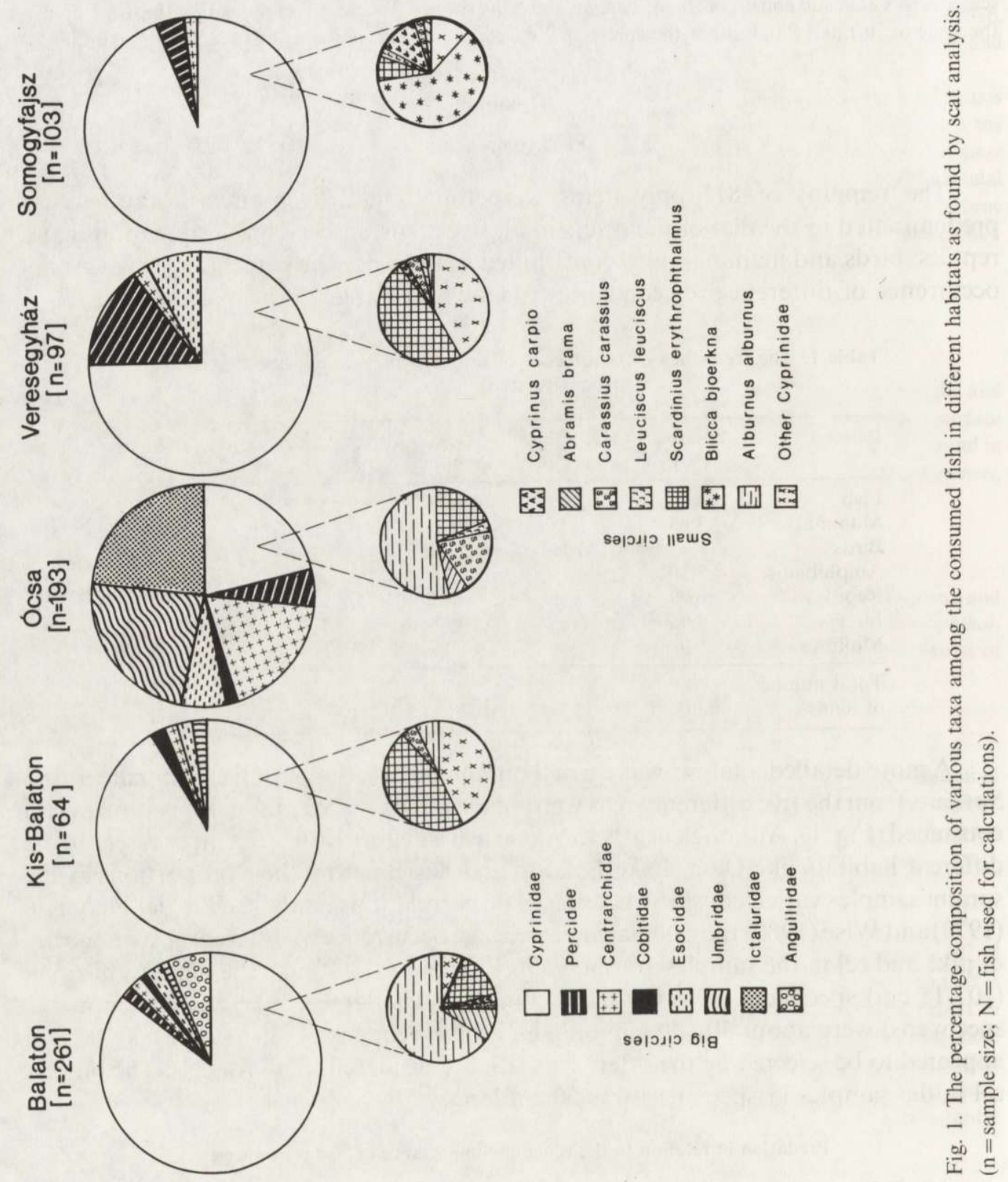

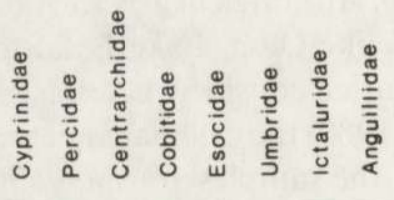

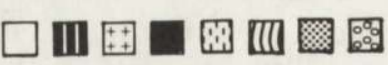
รә|गมा 6!8 


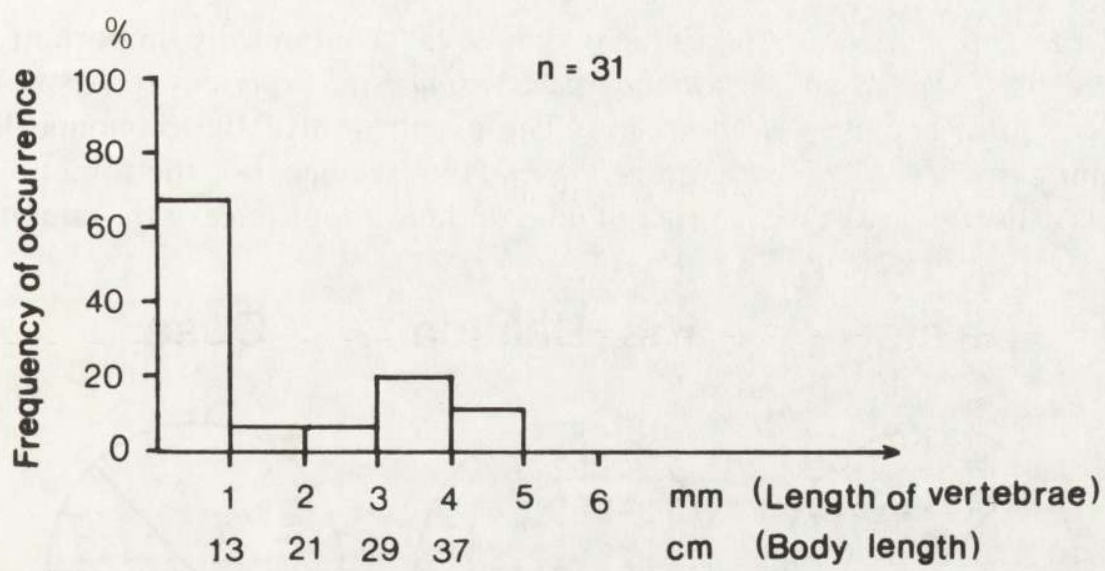

Fig. 2. The frequency of occurrence ( $\%$ ) of different size categories of pike (Esox lucius) as determined from body length $(\mathrm{cm})$ and length of the vertebrae $(\mathrm{mm})$ found in the scats. $(\mathrm{n}=$ sample size: $\mathrm{N}$ pikes used for calculations).

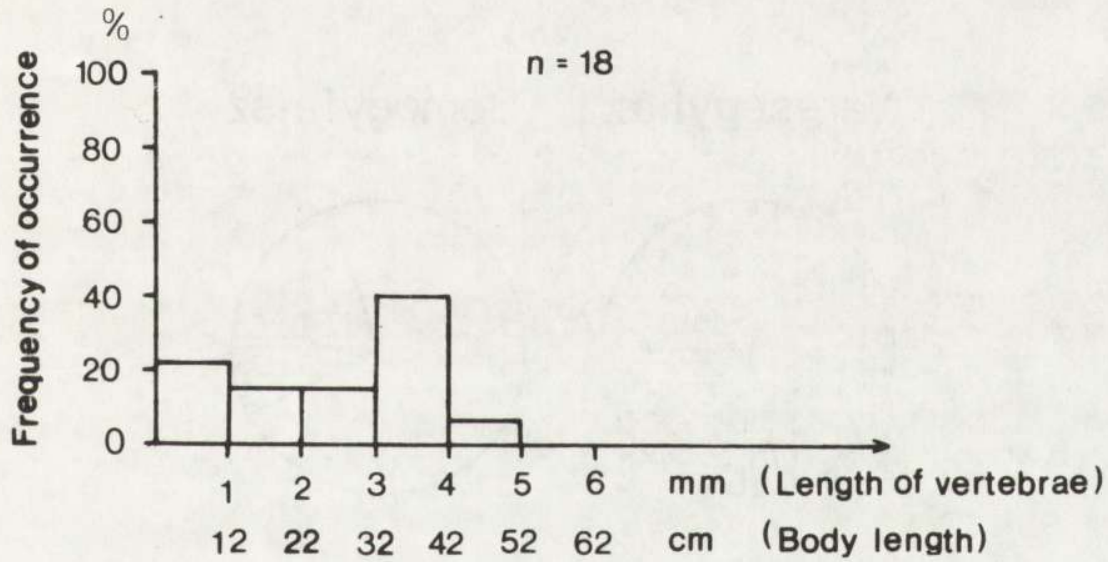

Fig 3. The frequency of occurrence $(\%)$ of different size categories of eel (Anguilla anguilla) as determined from body length $(\mathrm{cm})$ and the length of the vertebrae $(\mathrm{mm})$ found in the scats. $(\mathrm{n}=$ sample size; $\mathrm{N}$ eels used for calculations)

spraint samples. Of the eight families, two, namely Centrarchidae and Ictaluridae are considered as pests and a further two, Umbridae and Cobitidae have no economic importance. Of the family Percidae, which includes noxious and indifferent species as well as economically very important species, only the remains of Perca fluviatilis and Acerina cernua were found. Perca fluviatilis is a well-known predator of brood and Acerina cernua has no economic importance. Besides, within the family Percidae the contribution of Perca fluviatilis to the composition of food was much greater than that of Acerina cernua. All species of the families Anguillidae and Esocidae are economically important. 
Of the cyprinids, we found the remains of economically important species (Abramis sp., Carassius sp., Scardinius sp., Cyprinus sp., Leuciscus sp.) as well as the indifferent Alburnus and Blicca species. The proportion of the economically most important carp (Cyprinus carpio) was 3.05\% (13 specimens) of the total number of cyprinids in the five areas, while fishes of no economic importance of the same category comprised over $50 \%$ (Fig. 4).
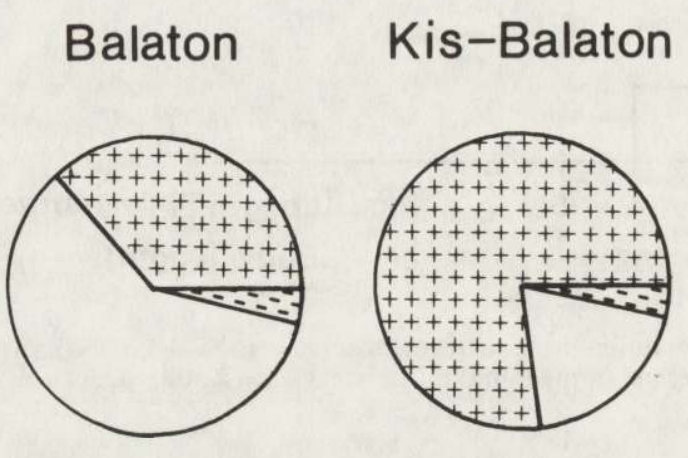

\section{Ócsa}
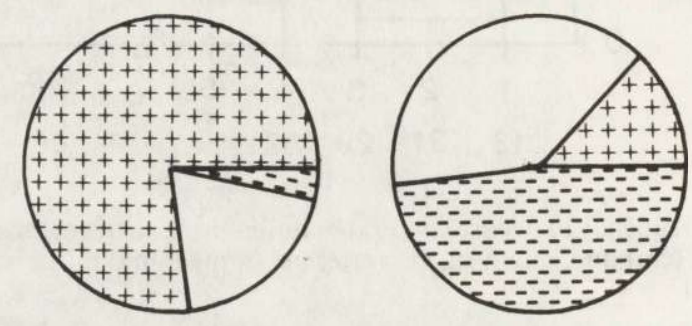

Veresegyház Somogyfajsz
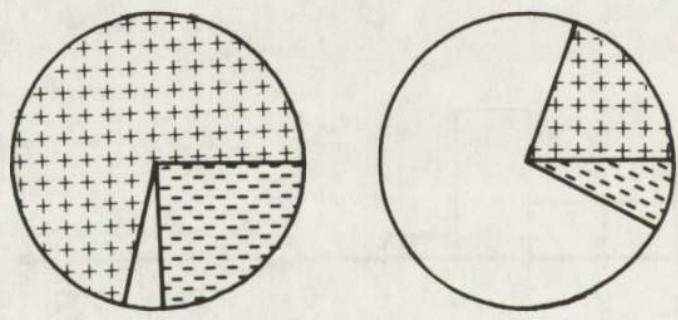

Economically important species

$\square$ Economically indifferent species

E-- Economically noxious species

Fig. 4. The distribution of tish prey species among the three classes of different economic importance. (sample sizes: same as in lig. 1).

\section{Discussion}

It is clear from the present study that the availability of a particular prey category is the most important factor influencing the composition of the food of otters. Our finding is in good agreement with the data from other authors obtained in very 
different habitat types (Erlinge 1967, 1968, 1969, Chanin 1981, Jenkins 1980). This statement appears to be true even for the populations of fish prey within the different prey categories.

In undisturbed natural aquatic habitats like Ócsa, where neither commercial nor sport-fishing and only natural animal populations can be found, the contribution of non-fish prey can be as much as about $18 \%$ of the total number of food items. A similar proportion of non-fish prey categories were found in the Somogyfajsz pond where the natural populations were still dominant over the introduced fish species and only angling is permitted on the pond. In habitats like the Veresegyház pond or Lake Balaton in this study, where the shore and water surface itself is heavily used by man, the occurrence of amphibians, reptiles, birds, molluscs and large aquatic insects was relatively low compared to the natural water bodies. Large numbers of fish are introduced every year into both Lake Balaton and the Veresegyház pond and as a result, predation on fish by otters is heavy. The Kis-Balaton Nature Reserve is in an intermediate position between natural water bodies and highly cultivated areas and this is also reflected by the moderately low $(13 \%)$ proportion of non-fish prey items found in otter spraints collected in this area.

The determination of food composition from the relative abundance of prey species is also true for the composition of fish prey of otters. The most homogeneous distribution was found in samples from Ócsa which was the most natural and least disturbed habitat in our study. In all five areas high variances were found in the proportion of different fish species in the diet and this shows that otters in general have no preference for any particular fish species (Erlinge 1967).

Within the economically important fish prey species studied, no preference for larger specimens was observed. On the contrary, otters appear to prefer smaller pike (Esox lucius) to medium or larger ones and displayed a weak preference for medium-sized eels (Anguilla anguilla) and small cyprinids (Erlinge 1960, Jenkins 1980).

Economically indifferent and noxious fish species were dominant in the otters' diet in three of the five study areas. At the remaining two, at Veresegyház and the Kis-Balaton Nature Reserve the economically important species are predominant in the stock and therefore the choice of prey within the fish stock is limited for the otter.

A major conclusion that can be drawn from our observations (on the proportion of fish and the economically important fish prey categories in the different habitats) is that it is highly recommendable for fish farmers to preserve the natural fish and non-fish fauna around and in their ponds as much as possible. This way non-fish prey populations may serve as "buffers" protecting by their presence the fish stock from depredation by otters (Erlinge 1967).

Acknowledgements: We wish to thank Dr. A. Demeter of the Hungarian Natural History Museum and Dr. G. Kemenes of the Balaton Limnological Research Institute for critically reading the manuscript and making valuable suggestions on early drafts of it. 


\section{References}

Berinkey L. 1966. Halak. Akadémiai Kiadó, Budapest: 1-138. [In Hungarian]

Chanin P. 1981. The diet of the otter and its relations with the feral mink in two areas of south-east England. Acta theriol. 26: 83-95.

Dyk V. 1956. Nase ryby. Praha: 126-127. [In Czech]

Erlinge S. 1967. Food habits of the fish-otter Lutra lutra L. in South Swedish habitats. Viltrevy 4: $371-443$.

Erlinge S. 1968. Food studies on captive otters (Lutra lutra L.). Oikos 19: 82-98.

Erlinge S. 1969. Food habits of the otter Lutra lutra L. and Mustela vison Schreber in a trout water in southern Sweden. Oikos 20: 1-7.

Frost G. A. 1928. A comparative study of the otoliths of the neopterygian fishes. Annales and Magazine of Natural History 15: 152-163.

Jenkins D., Walker J. G. K. and McCowan D. 1979. Analysis of otter (Lutra lutra) and mink (Mustela vison) faeces from Deeside. N.E. Scotland. J. Zool., Lond. 187: 235-244.

Jenkins D. and Harper R. J. 1980. Ecology of otters in northern Scotland. 2. Analysis of otter (Lutra lutra) and mink (Mustela vison) faeces from Deeside, N.E. Scotland in 1977-1978. J. Anim. Ecol. 49: $737-754$

Lagler K. F. and Ostenson B. T. 1942. The early spring food of the otter in Michigan. J. Wildl. Manage. 6: $244-254$.

Marz R. 1987. Gewoll- und Rupfungskunde. Akademie-Verlag, Berlin: 1-398.

Mason C. F. and Macdonald S. M. 1986. Otters: Ecology and conservation. Cambridge Univ. Press, Cambridge: 1-236.

Rowe-Rowe D. T. 1977. Prey capture and feeding behaviour of South African otters. Lammergeyer 23: $13-21$.

Tumanov I. L. and Smelov V. A. 1980. The food connections of the mustelids in the North-West of the R.S.F.S.R. Zool. Zh. 59 (10): 1536-1542. [In Russian with English summ.]

Waisfeld M. A. 1973. The otter (Lutra lutra) in the Arkhangelsk Oblast. Bull. Mosk. Obšč. Ispit. Prir. Otd. Biol. 78, 1: 1-16. [In Russian with English summ.]

Webb. J. 1976. Otter spraint analysis. The Mammal Soc., Reading: 1-13.

Wise M. H. 1980. The use of fish vertebrae in scats for estimating prey size of otters and mink. J. Zool., Lond. 192: $25-31$.

Received 4 August 1989, accepted 2 February 1990. 